\title{
Research on Civil Engineering Structure Design based on Safety and Economy
}

\author{
Fangfei Dong ${ }^{1}$ \\ Xijing University, 710123, Xi'an, China \\ e-mail: 44172812@126.com \\ Shidan $\mathrm{He}^{3}$ \\ Xijing University, 710123, Xi'an, China \\ e-mail:1546653654@qq.com
}

\author{
Xiaofang $\mathrm{Li}^{2}$ \\ Xijing University, 710123, Xi'an, China \\ e-mail: lixiaofangxijing@126.com
}

\begin{abstract}
The safety and economy have the most important position in the whole design of civil engineering structures. In this paper, the main problems in the design of civil engineering structures in China are analyzed, which mainly is the overall design engineering structure is not strong enough, the lack of structural design specification and the durability of civil structures, etc. The method of improving the safety and economy of civil engineering structures is proposed. Including improve the corresponding theoretical requirements, the design documents should be noted and tried to achieve accurate and comprehensive. For how to improve the economic method in civil engineering structure design, the design method is required to carry out a comprehensive evaluation of the design scheme, and the design idea should be flexible. At last, the safety accumulation of multi parameter design is analyzed and a method to solve the problem is put forward to improve the economy.
\end{abstract}

Keywords-Civil engineering;structural design;safety; economy

\section{INTRODUCTION}

The structural design of civil engineering design is mainly related to the safety and economic issues. At present, China's civil engineering accidents occur frequently, which has brought huge economic losses to our country. In order to reduce the civil engineering accident, it requires designers to ensure the safety of civil engineering structures under the premise, but also taking into account the civil engineering structures have a certain economy of which is for civil engineering industry is a challenge.

Civil engineering material is a variety of materials and products used in civil engineering, it is the material basis of all civil engineering. All of the buildings, bridges, roads, etc. are designed and constructed by several different materials, it occupies an extremely important role in China's modernization construction. Therefore, the correct selection and rational use of civil engineering materials, security of the whole civil engineering, practical, beautiful, durable and has a great significance.

Traditional civil engineering materials include: steel, wood, masonry materials, rigid gas inorganic cementitious materials, cement, mortar, concrete, polymer materials, asphalt and asphalt mixture as well as other building functional materials and so on. All these conventional civil engineering materials brought to mankind material civilization and to promote the progress of human civilization, but its production, use and recycling, not only consume a lot of resources and energy, but also brings environment pollution and other negative effects.

In twenty-first Century, people have to face the pressure of population, resources and environment, so it is urgent to find effective construction materials to coordinate the relationship between resources and environment, so that it can not only waste resources and protect the environment. In order to achieve the above objectives, the development, production and application of ecological building materials products, and the optimization design of the ecological environment of human settlements, are the research areas that the society must be involved in the future, will be paid more and more attention, and will become the hot spots in the future development of ecological building materials. To adapt to the traditional building materials to meet the needs of economic growth and sustainable development, we must make independent innovation, upgrade the traditional building materials industry with high and new technology, lead to product upgrading, improve product performance and price ratio, continue to play an important role in China's economy in building materials industry.

\section{THE CHARACTERISTICS AND SITUATION OF CIVIL ENGINEERING STRUCTURAL DESIGN}

With the continuous improvement of people's needs, people hope to highlight some of the elements they want to integrate in the building, which prompted the construction industry to take advantage of the structural design of civil engineering to complete personalized products. Now there have been some unique shape, large-scale buildings in the society, and some even become local landmarks, tourist attractions, etc., which undoubtedly shows the heavy share position in today's society of civil engineering structures design. Nonetheless, civil engineering structure design should be continue to modify and improve itself in accordance with the needs of their own situation and society, to better adapt to changing social development, to better meet the needs of contemporary people's physical and psychological. Civil engineering structural design is a special kind of art, it is primarily designed for the specific circumstances of the building program and developed, and this is different from other design, the mainly performance in the following: 


\section{A. Safety aspects}

Civil engineering structural design is a large project, it is necessary to have quality materials, solid buildings to maintain. So, when part of the structure is damaged, the buildings will not immediately collapse and cause serious accidents. Moreover, today's civil engineering has been applied to the level of disaster prevention, not only for natural disasters but also including man-made disasters. For example: before the earthquake, the people who do not have good shelter, and now the building has to establish some places to provide emergency shelter to the masses. Moreover, with the improvement of science and technology, people began to use new theoretical knowledge and technology to design projects, such as use the viewpoint of statistics, research can lead to damage to the building for various reasons, and the reasons for the classification, the laws of probability of occurrence and the occurrence of the reasons for statistical and analysis, provide some reference data analysis to improve the safety of civil engineering.

\section{B. The price advantage}

With respect to some use high-tech materials industry, civil engineering used by the steel, sand and other materials are readily available, and these materials market is large, so the price of materials is relatively cheap. Moreover, high technology material has its own advantages, such as light weight, environmental protection, but these materials are just introduced into this highly competitive market, there is no fixed customer base, so the scope can be applied is not large. This two points to highlight the civil engineering in the economy ahead of other high-tech materials design.

For this reason, people began to research and develop new materials, looking for the requirements material that meets the performance without destroying the environment, but also improve the "sustainable development" material environment. "Green material" was first proposed at the 1988 International Symposium on material subject, and then in 1992 the United Nations Environment and Development Conference was held, and establish the "Sustainable Product Development" working group in 1994. Countries have developed a "green building" performance standards. Technical workers in the domestic civil engineering materials are also committed to the development of new materials, and made a series of research results. Here, we start from the traditional civil engineering material, and then extended to the sustainable development strategy of engineering materials.
TABLE I. CATEGORY OF CIVIL ENGINEERING MATERIALS

\begin{tabular}{cccc}
\hline No & Type & color & species \\
\hline \multirow{2}{*}{ Organic } & Metallic materials & black & Steel, iron \\
& Non-ferrous metal & colored & Aluminum \\
& Plant material & Timber bamboo \\
Inorganic & $\begin{array}{c}\text { Bituminous } \\
\text { Materials }\end{array}$ & Petroleum pitch \\
& $\begin{array}{c}\text { Polymer Materials } \\
\text { Metallic }\end{array}$ & Plastic binder \\
& $\begin{array}{c}\text { composites } \\
\text { Non-ferrous } \\
\text { composites }\end{array}$ & $\begin{array}{c}\text { Polymer Concrete } \\
\text { Steel fiber reinforced } \\
\text { concrete }\end{array}$ \\
\hline
\end{tabular}

TABLE II. STATISTICS OF STEEL CONSUMPTION

\begin{tabular}{ccccc}
\hline Years & $\mathbf{1 9 9 9}$ & $\mathbf{2 0 0 0}$ & $\mathbf{2 0 0 1}$ & $\mathbf{2 0 0 2}$ \\
\hline $\begin{array}{c}\text { Build construction } \\
\text { steel consumption } \\
\text { Proportion }\end{array}$ & 6315 & 7335 & 8980 & 10523 \\
$\begin{array}{c}\text { House construction } \\
\text { steel consumption }\end{array}$ & 3906 & 4647 & 5337 & 6595 \\
Proportion & $38.6 \%$ & $37.7 \%$ & $40.3 \%$ & $47.1 \%$ \\
\hline
\end{tabular}

TABLE III. STATISTICS OF CEMENT PRODUCTION

\begin{tabular}{ccccc}
\hline Years & $\mathbf{1 9 9 9}$ & $\mathbf{2 0 0 0}$ & $\mathbf{2 0 0 1}$ & $\mathbf{2 0 0 2}$ \\
\hline output & 57300 & 59700 & 66104 & 72500 \\
$\begin{array}{c}\text { Transport loss } \\
\text { amount }\end{array}$ & 2808 & 2925 & 2640 & 2900 \\
$\begin{array}{c}\text { Transportation } \\
\text { ratio cases }\end{array}$ & $4.9 \%$ & $4.9 \%$ & $4.0 \%$ & $4.0 \%$ \\
\hline
\end{tabular}

\section{Adaptability}

With the progress of science and technology, civil engineering gradually combine with some new elements to create a better one and meet the different needs of the design. For example: When you want to analyze the structure of the building, people will use the existing technology to analysis data and modeling, and the model can be made to be tested to see whether the building is designed to withstand the destruction of natural environmental factors, this process will need to use precise computer measurement techniques. Integrating these techniques into civil engineering designs not only can improve the civil engineering design, but also can be better applied to other areas of the civil engineering. 
TABLE IV. STATISTICS OF CEMENT CONSUMPTION

\begin{tabular}{ccccc}
\hline Trade & Industry & $\begin{array}{c}\text { Building } \\
\text { industry }\end{array}$ & $\begin{array}{c}\text { Transport } \\
\text {-ation }\end{array}$ & Agriculture \\
\hline $\begin{array}{c}\text { Cement } \\
\text { consumption }\end{array}$ & 13000 & 37000 & 1100 & 21800 \\
$\begin{array}{l}\text { Accounting } \\
\text { for the total } \\
\text { proportion }\end{array}$ & $16 \%$ & $45 \%$ & $1 \%$ & $27 \%$ \\
\hline
\end{tabular}

\section{CURRENT ISSUES OF CIVIL ENGINEERING STRUCTURAL DESIGN}

\section{A. The overall firmness is not enough}

In the actual use of the building the quality of the local safety will not affect the overall buildings safety, but the overall firmness of the building is safety lifeline. For the overall firmness of the building, the design requirements of civil process must have their own redundancy and good ductility. So the overall firmness is the most criterion for evaluating the quality of a building, and good design can resist the consequences of various natural disasters.

\section{B. Safety specifications}

From the integrity of structural engineering design, the safety design involves in many factors. The most important factor effecting the structural safety of the building is carrying capacity, durability and firmness. The safety regulations of Civil Engineering of loopholes primarily due to lower bad authoritative and binding. Therefore, standardized security settings of civil engineering structures below the abroad norm caused a lot of serious problems related to cracking and deformation.

\section{Lack of durability}

In our country, the durability of civil engineering structural mainly refers to the durability under sustained load and durability for the environment and other factors basically did not do much consideration. Structural design requirements vary with climate change, in China, there is no clear legal provisions, which is a serious lack of standardization.

\section{METHODS TO IMPROVE THE SAFETY OF CIVIL ENGINEERING STRUCTURES}

\section{A. Ensure that the design of security from the management}

When in choice of design units, Managers must to choose a guaranteed, stronger and management of advanced design units. Because such design units generally have a wealth of design experience and advanced design equipment, while they also have advanced management and professional design staff quality are higher. Therefore, this can improve the design quality in the design, structure design to ensure safety.

\section{B. Regular inspection and maintenance}

The whole building project is not terminated at the completion of construction works project, which is a longterm project, the completion of the project is only a part of the project, the latter part of the project plays a very important role, and this latter part of the work is to carry out regular testing and maintenance. Regular testing and maintenance is an essential step in the project, particularly for some poor environmental engineering, process engineering will make good quality is affected by environmental conditions. And project detection and maintenance is also required to support law, the law make provision for the project to be performed on the different nature of the project, therefore, the enterprise have to do a good job on supervision and maintain the project preparation.

\section{Improve and enhance the corresponding theory}

In the design of appropriate design theory to improve and enhance, which requires some conceptual design for more in-depth understanding and maintaining a clear design ideas on this basis. So the conceptual structure design has become a guarantee for the safety design of the structure.

\section{Focus on design documents description}

Illustrate the design document is mainly construction workers provide operating instructions, the designers should pay attention to the quality of statement should be both simple and accurate, so as to enable the different quality construction workers can understand the design content. Especially in complex design should pay more attention to the documentation, in order to ensure consistency of the safety in construction and design of the expected direction.

\section{E. Achieve accurate and comprehensive in the design}

Scientific and systematic management should be used in the design of the whole structural design project segments. This will help to improve each subproject design and review can ensure the design will not miss any of the items and calculate the content. However, many design accidents are caused by the omission of a particular project or calculated design parameter. Therefore, meticulous and strict management, monitoring and auditing in the design of the whole process would be necessary.

\section{METHODS TO IMPROVE THE ECONOMY OF CIVIL ENGINEERING STRUCTURES}

\section{A. Comprehensive assessment}

Comprehensive evaluation and selection of design schemes is to control the economic performance before the design of the project. The purpose is to make a clear economic indicator for the design of the professional design department.

\section{B. Reduce the cost of engineering structures}

As much as possible to use a flexible design ideas and methods in the building design, do not invariably use the standard diagram design. Although this design can reduce design effort and reduce the error rate, but lack of innovation, is not conducive to lowering the cost of engineering structures. Therefore, the design should give full play to the designer's design capacity, the use of reasonable structural design method can ensure safety and guarantee the economy. 


\section{Cooperation and communication}

Coordinate and communicate during the construction progress and cooperative relationship between the various relevant departments to help companies get more accurate data and information so you can reduce costs. We all know that the civil engineering structures involves not merely the simple construction problem, it generally contain a large number of auxiliary data, supporting information and data monitoring. Therefore, the designer should be communicate and cooperate with the relevant departments in the design, so that they can obtain more comprehensive information and data, so as to improve the design of the economy.

\section{Parameter control}

Design problems often occur accumulate more secure design parameters, such as reinforced concrete structure design will involve large costs and safety factors, including material, size and reinforcement quantity. These parameters will directly affect the safety and economic structures. So in the design parameters required to evaluate multiple design options and choices, it is possible with the main parameter to control the coordination of economic and safety of such a comprehensive measure to be selected by changing the parameters and selectivity is more accurate and reliable. In the economic evaluation, for multi-parameter problems are often a major advantage of using a proportional relationship parameter to indicate the other parameters, that is, using an equation to represent the necessary values and values of other parameters necessary parameters are thus obtained to control the economy.

\section{CONCLUSIONS}

During the construction of engineering structures should be designed to adhere to the principle of safety first, only to safety as a precondition to promote the comprehensive development of enterprises, in order to ensure the building design and construction economy. Improve the design of personnel expertise and capabilities, and require compliance with safety design specifications while improving the quality and safety of civil engineering design personnel to identify the ability to ensure the safety of every architectural structure. On the basis of safety of the building, based on the basis of cost savings. Civil engineering structural design is to ensure construction safety and economy as the fundamental, only the two taken together, we can achieve safety and economic harmony and unity.

\section{REFERENCES}

[1] Wang Yan-kun. Research on safety and economy of civil engineering design. Technology Outlook.2015, pp. 49-50

[2] Yang xiao-feng. How to guarantee the safety and economy of civil engineering design work. Shanxi architecture. 2014, pp.29-30

[3] Hao min. Safety and economy of civil engineering structure design. Heilongjiang science and technology information. 2012. pp. 27-28

[4] Zhang wan-he. Safety and economy in the design of civil engineering structures. Technology Outlook.2015, pp. 12-13

[5] Li xiu-yu. Research on safety and durability of Civil Engineering. Innovation and Application of Science and technology

[6] Ye Run-qin. The application of economic structure in the structural design of building engineering. Science and technology information. 2012, pp.08-09

[7] Ma shuang. Research on safety and durability of civil engineering structures. Science and technology. 2008, pp.06-07

[8] Ren xi-lu. Research on safety of civil engineering structures. Water conservancy construction and management. 2008, pp.14-15

[9] Wang zhong-wei. Discussion on safety and economy of civil engineering structure design. Engineering Science and technology. 2012, pp.48-49

[10] Zhu lai-qin. Problems and Countermeasures in the design of civil engineering $\quad$ structures. $2011, \quad$ pp.21-22. 